\title{
Rhenium(I) Complexes with Pincer Ligands as a New Class of Potential Antitumor Agents ${ }^{+}$
}

\author{
Diana V. Aleksanyan ${ }^{1, *}$, Svetlana G. Churusova ${ }^{1}$, Ekaterina Yu. Rybalkina ${ }^{2}$ \\ and Vladimir A. Kozlov ${ }^{1}$ \\ 1 Nesmeyanov Institute of Organoelement Compounds, Russian Academy of Sciences, ul. Vavilova 28, \\ Moscow 119991, Russia \\ 2 Blokhin National Medical Research Center of Oncology of the Ministry of Health of the Russian \\ Federation, Kahirskoe shosse 23, Moscow 115478, Russia \\ * Correspondence: aleksanyan.diana@ineos.ac.ru \\ + Presented at the 2nd Molecules Medicinal Chemistry Symposium (MMCS): Facing Novel Challenges in \\ Drug Discovery, Barcelona, Spain, 15-17 May 2019.
}

Published: 8 August 2019

\begin{abstract}
Transition metal complexes attract continuous research interest as potential antitumor agents. The most popular compounds are ruthenium, gold, titanium, osmium, iridium, zinc, and palladium complexes, which have already displayed cytotoxic features that are not typical for classical platinum-containing chemotherapeutic agents. Substantially lower attention is drawn to organometallic compounds of rhenium. However, the known examples of cytotoxic organometallic rhenium derivatives with bidentate heterocyclic, organophosphorus, labile alkoxide, and hydroxide ligands render further studies in this field very promising. As for their analogs with multidentate ligands, a literature survey has revealed only a few examples of cytotoxic rhenium complexes, whereas the antitumor activity of cyclometallated derivatives has not been studied at all. At the same time, it is known that the use of pincer-type ligands having specific tridentate monoanionic frameworks, which offer multiple options for directed structural modifications, allows one to finely tune the thermodynamic and kinetic stability of the resulting metal complexes. Therefore, we synthesized and studied the cytotoxic properties of a series of rhenium(I) complexes with tridentate pincer-type ligands based on functionalized carboxamides bearing ancillary donor groups both in the acid and amine components. It was shown that the target complexes can be obtained not only by the conventional solution-based method, but also under solvent-free conditions according to the solid-phase methodology recently developed in our group. The results obtained were used to define the main structure-activity relationships for a principally new class of potential antitumor agents and to choose the most promising compounds for further studies in order to create new pharmaceuticals.
\end{abstract}

Keywords: antitumor agents; rhenium; pincer complexes

Funding: This work was supported by the Russian Science Foundation, project no. 18-73-00310.

(C) 2019 by the authors. Licensee MDPI, Basel, Switzerland. This article is an open access article distributed under the terms and conditions of the Creative Commons Attribution (CC BY) license (http://creativecommons.org/licenses/by/4.0/). 